\title{
Purifikasi Biogas dengan Variasi Ukuran dan Massa Zeolit terhadap Kandungan $\mathrm{CH}_{4}$ dan $\mathrm{CO}_{2}$
}

\author{
Denny Widhiyanuriyawan, Nurkholis Hamidi, Candra Trimandoko* \\ Teknik Mesin Universitas Brawijaya Indonesia, MT Haryono, 167 - Malang (65145) \\ - Indonesia \\ E-mail: trimandoko@gmail.com
}

\begin{abstract}
Nowadays, the development of the renewable energy very rapidly. It is driven by the nature of the renewable energy that has been proven to be cleaner than conventional energy, so an increase in the use of renewable energy continues to rise. Biogas is produced from biological processes (anaerobic digester) is capable of producing gas such as $\mathrm{CH}_{4}, \mathrm{CO}_{2}, \mathrm{H}_{2} \mathrm{~S}$, and other gases. Therefore it is very important to make the process of refining the biogas. In this research, using the biogas purification process purification method stratified, with a solution of sodium hydroxide with zeolite is purified again and again purified with activated charcoal, hence the storied purification. In this study focused on the observation of zeolite as an adsorbent, the size of the fine and coarse zeolite, and zeolite are varied mass of 50 grams, 100 grams and 150 grams. In 60 minutes, the best result obtained on zeolites fine size with a mass of 150 grams of $\mathrm{CO}_{2}$ obtained down to $4.07 \%$, but the pressure dropped to $0.65 \mathrm{kPa}$. With the size of the coarse zeolite at $4.26 \% \mathrm{CO}_{2}$, with a pressure drop of $0.84 \mathrm{kPa}$. After the purification process, zeolite proved to be hidrofill with the content of the zeolite fine biggest water with $5.4 \%$.
\end{abstract}

Keywords: Zeolite, $\mathrm{CO}_{2}, \mathrm{CH}_{4}$, biogas purification, gas preassure.

\section{PENDAHULUAN}

Dewasa ini perkembangan mengenai energi terbarukan (renewable energy) sangatlah pesat. Hal ini didorong oleh sifat energi terbarukan yang telah terbukti lebih bersih dari energi konvensional, sehingga peningkatan dalam penggunaan energi terbarukan terus meningkat. Secara sederhana energi terbarukan didefinisikan sebagai energi ramah lingkungan yang berasal dari proses alam dan dapat digunakan secara berkelanjutan. Biogas merupakan salah satu energi terbarukan yang sangat berpotensi untuk dikembangkan dan terjamin kontinuitasnya [1].

Biogas berasal dari bahan - bahan organik yang difermentasikan oleh aktivitas anaerobik dari bakteri metana yang didapatkan dengan cara metanogen seperti Methanobacterium sp. Metanogen sendiri adalah sebuah proses yang terakhir pada rantai mikro-organisme yang lebih rendah dekomposisi bahan organik dan kembali produk ke lingkungan. Dalam proses terbentuknya, biogas berlangsung dalam keadaan tertutup [2].
Dari aktivitas anaerobik oleh bakteri metana, biogas mampu menghasilkan gas gas seperti $\mathrm{CH}_{4}, \mathrm{CO}_{2}, \mathrm{H}_{2} \mathrm{~S}$, dan gas - gas lain. Dalam hal ini tentu saja yang dimanfaatkan adalah gas metana $\left(\mathrm{CH}_{4}\right)$, karena $\mathrm{CH}_{4}$ mempunyai nilai kalor yang tinggi sehingga dapat digunakan sebagai bahan bakar. Dekomposisi anaerob tersebut menghasilkan biogas yang terdiri dari $\mathrm{CH}_{4}(55$ $-75 \%), \mathrm{CO}_{2}(25-45 \%), \mathrm{N}_{2}(0-0.3 \%), \mathrm{O}_{2}$ $(0.1-0.5 \%), \mathrm{H}_{2} \mathrm{~S}(0.1-3 \%)$, dan $\mathrm{H}_{2}$ [3].

Kemurnian dari $\mathrm{CH}_{4}$ yang dihasilkan oleh biogas akan menjadi sangat penting, dikarenakan $\mathrm{CH}_{4}$ tersebut akan sangat berpengaruh terhadap nilai kalor yang dihasilkan. Sehingga $\mathrm{CH}_{4}$ yang dihasilkan perlu dilakukan pemurnian terhadap impuritas - impuritas yang lain [4]. Impuritas yang sangat berpengaruh terhadap nilai kalor pada biogas adalah $\mathrm{CO}_{2}$, keberadaan $\mathrm{CO}_{2}$ dalam biogas sangat tidak diharapkan, hal ini dikarenakan semakin tinggi kadar $\mathrm{CO}_{2}$ dalam biogas maka akan semakin menurunkan nilai kalor $\mathrm{CH}_{4}$ yang sangat mengganggu dalam proses pembakaran [5].

Metode pemurnian biogas adalah dengan melakukan absorbsi pada larutan 
kimia dan adsorbsi pada permukaan padat. Salah satu contoh absorbsi menggunakan larutan kimia adalah dengan larutan $\mathrm{NaOH}$, dimana biogas dilewatkan pada larutan $\mathrm{NaOH}$, sehingga terjadi reaksi antara zat pelarut dan zat yang terlarut [6]. Metode adsorbsi pada permukaan padat adalah salah satu metode yang efektif sebagai penyerap gas. Salah satunya yaitu dengan menggunakan batu zeolite [7], dalam prosesnya, adsorbsi pada biogas berlangsung pada pori - pori zeolit.

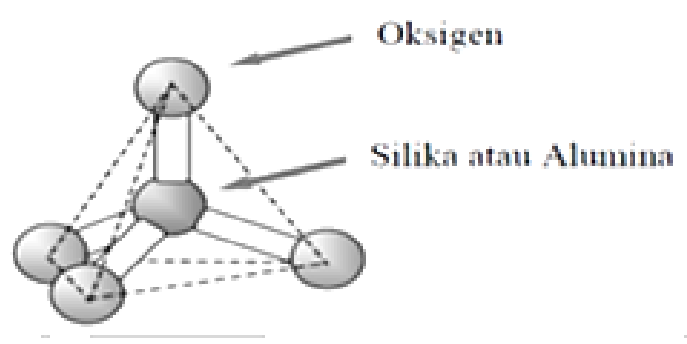

Gambar 1. Struktur $\mathrm{TO}_{4}$ Kimia Zeolit [8].

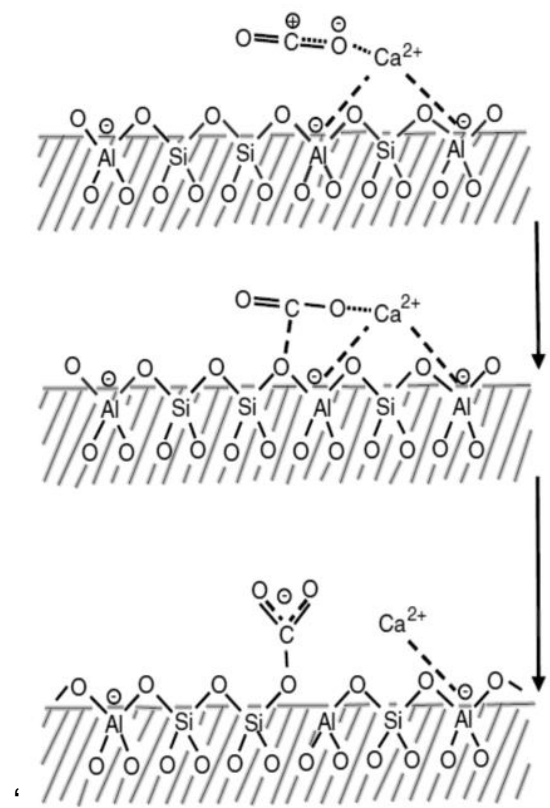

Gambar 2. Mekanisme adsorbsi $\mathrm{CO}_{2}$ oleh zeolit [9]
Afinitas zeolit untuk beberapa gas disebabkan oleh polaritas molekul yang teradsorbsi. Molekul-molekul yang memiliki momen quadrupole permanen besar mungkin berinteraksi kuat dengan gradien medan listrik yang disebabkan oleh pergerakan kation dari zeolit. Saat quadrupole gas tertentu bervariasi sebagai berikut: $\mathrm{CO}_{2}>\mathrm{CO}>\mathrm{N} 2>\mathrm{H}_{2}>\mathrm{CH}_{4} \approx$ $\operatorname{Ar} \approx \operatorname{Kr}[9]$.

Penyerapan zeolit pada $\mathrm{CO}_{2}$ ditunjukan oleh Gambar 2, karena polaritas yang dimiliki $\mathrm{CO}_{2}$ dimana atom $\mathrm{O}$ dengan muatan negatif cenderung mendonorkan muatan elektronnya pada kation - kation zeolit yang bermuatan positif pada permukaan zeolit $\left(\mathrm{Li}^{+}, \mathrm{Na}^{+}, \mathrm{K}^{+}\right.$, $\left.\mathrm{Ca}^{2+}, \mathrm{Sr}^{2+}, \mathrm{Ba}^{2+}, \mathrm{Cu}^{2+}, \mathrm{Zn}^{2+}, \mathrm{Mg}^{2+}\right)$. Sementara kation - kation pada zeolit terlebih dahulu ditarik oleh muatan oksigen pada struktur $\mathrm{SiO}_{4}$ atau $\mathrm{AlO}_{4}$, sehingga atom $\mathrm{C}$ pada $\mathrm{CO}_{2}$ menjadi tidak stabil karena atom $\mathrm{O}$ mendonorkan elektronnya, sehingga C cenderung ditarik dan berikatan dengan salah satu atom O pada struktur $\mathrm{SiO}_{4}$ atau $\mathrm{AlO}_{4}$ [8].

\section{METODE PENELITIAN}

Metode yang digunakan pada penelitian ini adalah experimental research. Dilakukan di Laboratorium Motor Bakar, Teknik Mesin, Universitas Brawijaya. Pada penelitian ini akan diuji pengaruh massa zeolit terhadap kandungan gas $\mathrm{CH}_{4}$ dan $\mathrm{CO}_{2}$ dalam proses purifikasi gas secara bertingkat dan kontinyu. Biogas yang digunakan merupakan campuran dari volume gas $\mathrm{CH}_{4}$ sebesar $80 \%$ dan volume gas $\mathrm{CO}_{2}$ sebesar $20 \%$ yang dicampur dengan gas mixer dan dialirkan secara kontinyu pada sebuah sistem yang bertingkat. tabung akrilik dengan diameter $11 \mathrm{~cm}$. Untuk instalasi penelitian yang digunakan ditunjukan pada Gambar 3.

Sistem terdiri dari 3 tabung akrilik dengan diameter $11 \mathrm{~cm}$, tabung 1 berisi larutan $\mathrm{NaOH} 30 \%$ dengan jumlah lubang bubble 30 sebagai absorben, tabung 2 berisi zeolit yang disusun dengan layer yang divariasikan massanya sebesar 50 gram, 100 gram, dan 150 gram dengan jenis ukuran zeolit coarse dan fine yang dipanaskan 
terlebih dahulu selama 120 menit pada temperatur $105^{\circ} \mathrm{C}$, tabung 3 berisi arang aktif 500 gram. Gas dialirkan pada sistem dan diukur kadar $\mathrm{CO}_{2}$ menggunakan Stargas analyzer. Sementara tekanan pada gas diukur menggunakan tranducer tekanan MPX 2010 GS dan di record dalam data logger. Sebelum dan setelah proses purifikasi kandungan kadar air dalam zeolit diuji menggunakan moisture analyzer.

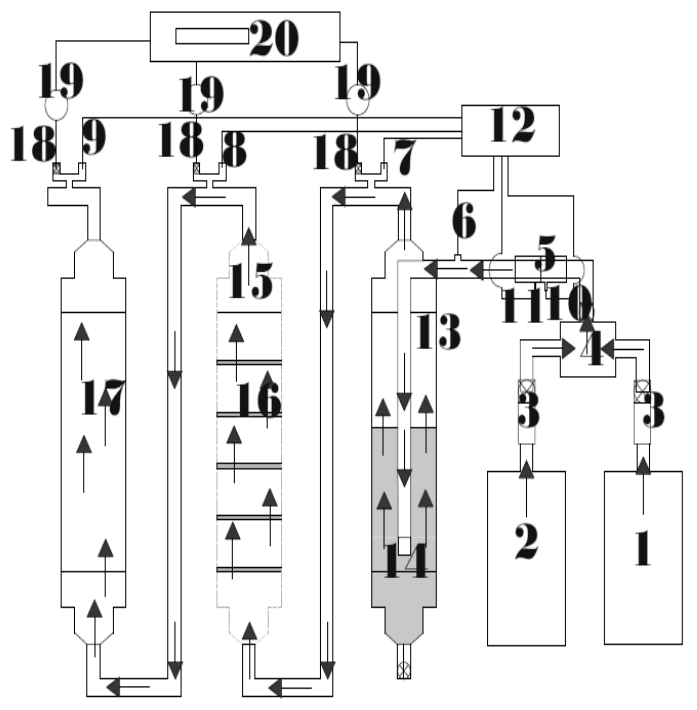

\begin{tabular}{|c|c|}
\hline Keterangan & 11. Tranducer 5 \\
\hline 1. Tabung $\mathrm{Gas} \mathrm{CH}_{4}$ & 12. Data Logger \\
\hline 2. Tabung Gas $\mathrm{CO}_{2}$ & 13. Tabung $\mathrm{NaOH}$ \\
\hline 3. Flowmeter & 14. Bubble Generator \\
\hline 4. Gas mixer & 15. Tabung Zeolit \\
\hline 5. Orifice & 16. Layer Zeolit \\
\hline 6. Tranducer 0 & 17. Tabung Arang Aktif \\
\hline 7. Tranducer 1 & 18. Katup Sampel Gas \\
\hline 8. Tranducer 2 & 19. Kantong Gas \\
\hline 9. Tranducer 3 & 20. Stargas Analyzer \\
\hline 10. Tranducer 4 & \\
\hline
\end{tabular}

Gambar 3. Instalasi penelitian

Langkah pengujian pada penelitian yaitu pertama alirkan gas $\mathrm{CH}_{4}$ dan $\mathrm{CO}_{2}$ ke dalam flowmeter dengan persentase debit 80\%:20\%. Kemudian gas akan tercampur pada gas mixer dan debit gas yang mengalir ke sistem diukur pada orifice. Pertama zeolit coarse yang digunakan dengan massa 50 gram, setiap 5 menit ambil gas pada kran sampel dengan kantong secar bersama - sama selama 60 menit. Setelah pengujian selesai uji kadar $\mathrm{CO}_{2}$ pada kantong gas dengan menggunakan stargas analyzer. Sesudah data dengan zeolit coarse 50 gram selesai lakukan pengambilan data dengan zeolit coarse 100 gram dan 150 gram. Kemudian lakukan pengujian menggunakan zeolit fine dengan massa 50 gram, 100 gram dan 150 gram.

Selama 60 menit pengujian berlangsung tekanan gas secara otomatis akan terukur pada tranducer tekanan MPX 2010 GS dan di record dalam data logger.

\section{HASIL DAN PEMBAHASAN}

Pada Gambar 4 a, b, dan c di atas adalah Gambar yang menunjukkan hubungan waktu terhadap penurunan kadar gas $\mathrm{CO}_{2}$ pada proses purifikasi menggunakan dua absorben, yaitu larutan $\mathrm{NaOH}$ dan zeolit selama 60 menit. Gambar 4 a menunjukkan penurunan kadar $\mathrm{CO}_{2}$ dari volume awal yaitu $19.6 \%$ yang turun menjadi $7.74 \%$ setelah melalui larutan $\mathrm{NaOH}$ atau $\mathrm{NaOH}$ mengurangi $60.05 \%$ dari volume awal $\mathrm{CO}_{2}$. Massa zeolit dengan ukuran coarse pada garis yang berwarna merah dan zeolit ukuran fine dengan massa 50 gram yang digunakan sebagai adsorben lanjutan setelah melewati larutan $\mathrm{NaOH}$. Kadar $\mathrm{CO}_{2}$ akan turun setelah melalui zeolit coarse sebesar $0.23 \%$ dari 7.74 $\%$ pemurnian yang dilakukan $\mathrm{NaOH}$, sementara zeolit fine menurunkan kadar $\mathrm{CO}_{2}$ sebesar $0.83 \%$ dari pemurnian yang dilakukan oleh $\mathrm{NaOH}$.Semakin lama waktu purifikasi maka, kemurnian dari $\mathrm{CH}_{4}$ akan semakin baik, dikarenakan semakin banyak $\mathrm{CO}_{2}$ yang akan terserap secara kontinyu pada rongga - rongga zeolit.

Gambar 4 b menunjukkan massa zeolit coarse dan fine yang ditambah menjadi 100 gram, dengan penambahan massa zeolit coarse membuat kadar $\mathrm{CO}_{2}$ turun sebesar $0.73 \%$ sampai dengan $1.04 \%$, zeolit fine 
menurunkan kadar $\mathrm{CO}_{2}$ sebesar $1.1 \%$ sampai dengan $1.32 \%$ dari pemurnian yang dilakukan $\mathrm{NaOH}$, penurunan kadar $\mathrm{CO}_{2}$ ini dikarenakan luas bidang kontak zeolit pada $\mathrm{CO}_{2}$ akan menjadi lebih banyak dengan massa zeolit yang ditambah.

a.

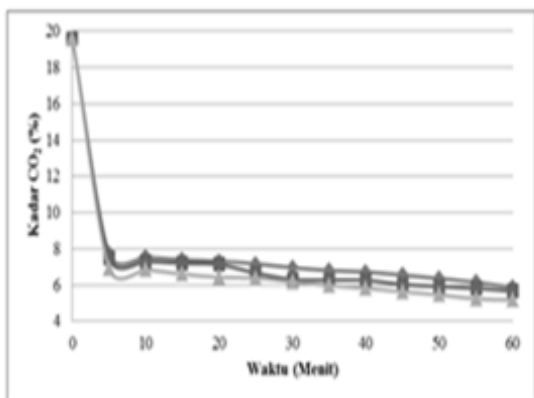

b.

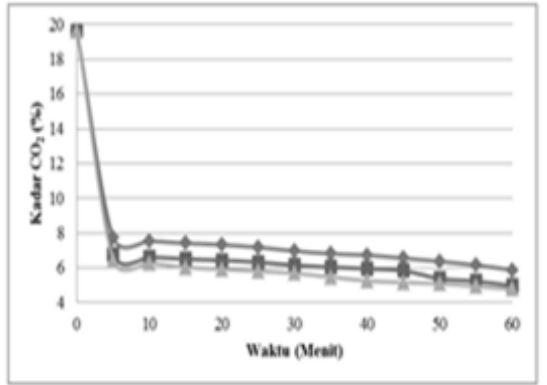

c.

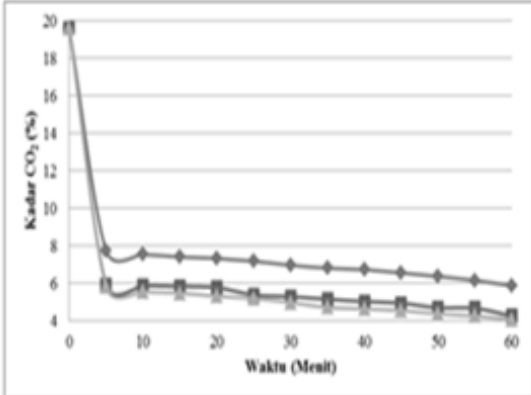

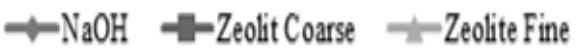

Gambar 4. Hubungan waktu terhadap kadar $\mathrm{CO}_{2}$ setelah dengan zeolit coarse dan fine pada (a) massa 50 gram, (b) massa 100

gram, dan (c) massa 150 gram

Gambar 4 c menunjukkan penambahan massa zeolit menjadi 150 gram, dengan 150 gram zeolit menambah kemurnian $\mathrm{CH}_{4}$ dengan menurunkan kadar $\mathrm{CO}_{2}$ hingga 4.26 $\%$ pada zeolit coarse dan $4.19 \%$ pada zeolit
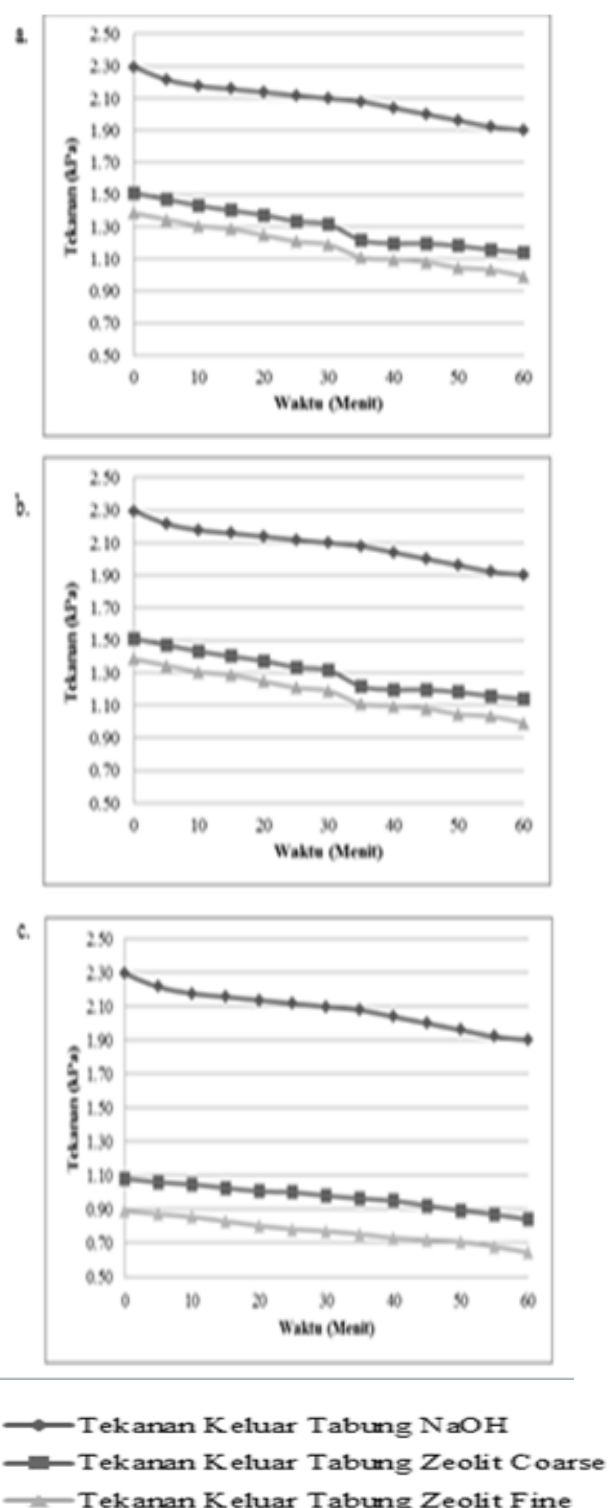

Gambar 5. Grafik hubungan waktu terhadap tekanan gas dengan zeolit coarse dan zeolit fine pada (a) massa 50 gram, (b) massa 100 gram, dan (c) massa 150 gram.

fine. Hal ini membuktikan bahwa dengan semakin banyak massa zeolit yang digunakan sebagai adsorben $\mathrm{CO}_{2}$ akan semakin baik, dikarenakan luasan bidang kontak terhadap gas $\mathrm{CO}_{2}$ semakin bertambah. Selama 60 
menit kadar kemurnian $\mathrm{CH}_{4}$ semakin baik, dengan menurunnya kadar $\mathrm{CO}_{2}$ yang terserap secara kontinyu oleh zeolite.Gambar 5 a menunjukkan bahwa dengan zeolit coarse dan fine dengan massa sebesar 50 gram, tekanan gas keluar dari tabung zeolite coarse sebesar $1.51 \mathrm{kPa}$ hingga $1.14 \mathrm{kPa}$ dan tekanan gas keluar tabung zeolit fine sebesar $1.38 \mathrm{kPa}$ sampai dengan $0.99 \mathrm{kPa}$, ini membuktikan bahwa dalam 60 menit gas $\mathrm{CO}_{2}$ terserap oleh zeolit yang mengakibatkan tekanan pada tabung purifikasi zeolit menurun.

Gambar 5 b menunjukkan bahwa penurunan tekanan pada zeolite coarse dan fine yang divariasikan sebesar 100 gram, dengan persentase kadar $\mathrm{CO}_{2}$ yang lebih baik dari kadar zeolit 50 gram. Pada Gambar 5 b membuktikan bahwa penurunan tekanan pada output zeolit lebih turun dari tekanan output tabung zeolit pada Gambar 5 a, hal ini menunjukkan bahwa gas $\mathrm{CO}_{2}$ yang terserap pada zeolit lebih banyak dengan tekanan yang terukur pada output tabung zeolit coarse sebesar $1.31 \mathrm{kPa}$ sampai dengan $1.02 \mathrm{kPa}$ dan tekanan pada output menggunakan zeolit fine sebesar $1.13 \mathrm{kPa}$ sampai dengan 0.84 $\mathrm{kPa}$.

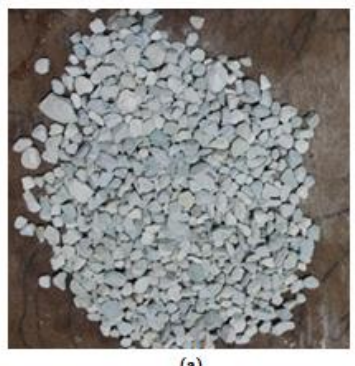

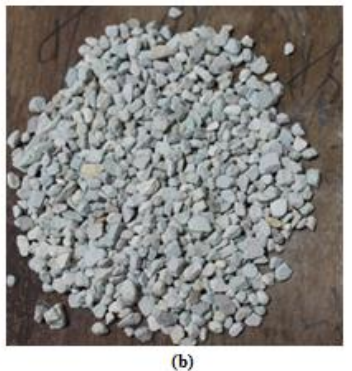

(b)
Gambar 6. (a) Zeolit sebelum purifikasi dan (b) Zeolit setelah purifikasi

Selain penurunan kadar pada $\mathrm{CO}_{2}$ yang diukur oleh stargas dan penurunan tekanan gas yang diukur dengan tranducer, terjadinya penyerapan $\mathrm{CO}_{2}$ oleh zeolit ditunjukkan oleh Gambar 6 a dan b, pada Gambar 6 b terlihat warna pada zeolit lebih keruh atau kusam jika dibandingkan dengan Gambar 6 a.

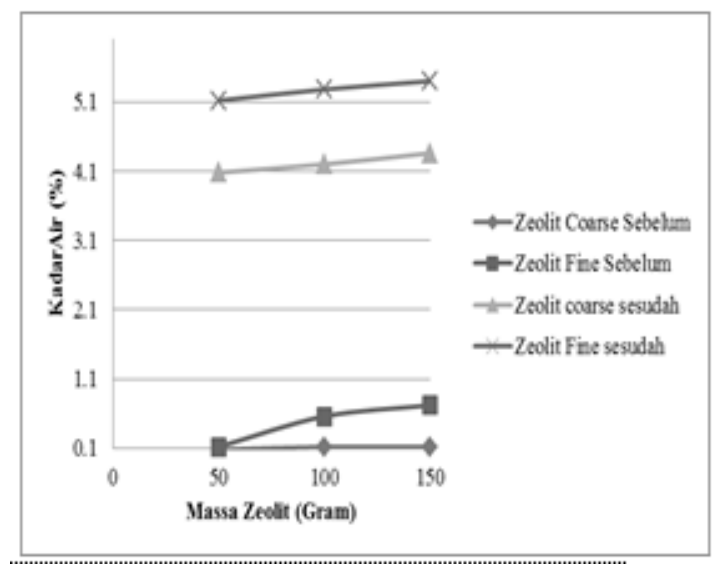

Gambar 7. Hubungan massa zeolit coarse dan fine terhadap kadar air untuk zeolit sebelum dan sesudah purifikasi

Gambar 7 di atas menunjukkan hubungan antara massa zeolit dan persentase kadar air, terlihat bahwa kadar air yang terdapat pada zeolit sebelum dipanaskan berada pada nilai dibawah $1 \%$ atau kadar air yang tertinggi pada zeolit fine dengan massa 150 gram sebesar $0.72 \%$. Setelah proses purifikasi, zeolit mengalami penyerapan kadar air yang nilainya lebih besar daripada kadar air sebeum purifikasi dengan kadar air terendah sebesar $4.08 \%$ pada zeolit coarse dengan massa 50 gram dan kadar air tertinggi pada zeolit fine dengan massa 150 gram sebesar $5.4 \%$. Hal ini menunjukkan bahwa kadar air yang terserap oleh zeolit mempengaruhi penyerapan $\mathrm{CO}_{2}$ oleh zeolit. Namun dengan penyerap air oleh zeolit dapat menyempurakan penyerapkan $\mathrm{CO}_{2}$ pada purifikasi bertingkat.

\section{KESIMPULAN}

1. Dengan pemberian, dan penambahan massa zeolit selama 60 menit, maka kandungan $\mathrm{CO}_{2}$ yang berhasil diserap oleh adsorben akan semakin banyak, dengan kadar $\mathrm{CO}_{2}$ terendah sebesar $4.26 \%$.

2. Dengan menggunakan zeolit dengan ukuran halus (fine) penyerapan $\mathrm{CO}_{2}$ lebih baik jika dibandingkan dengan ukuran coarse, dengan kadar zeolit terendah 
sebesar $4.19 \%$.

3. Terserapnya gas $\mathrm{CO}_{2}$ oleh adsorben membuat tekanan gas menurun, dengan dsorben zeolit coarse teknan gas terendah sebesar $0.84 \mathrm{kPa}$, sedangakan zeolit fine tekanan gas terendah sebesar $0.65 \mathrm{kPa}$.

4. Penggunaan zeolite sebagai adsorben selain berfungsi sebagai penyerap $\mathrm{CO} 2$ juga berfungsi untuk menyerap air dengan kadar air tertinggi terdapat pada zeolit fine 150 gram dengan $5.4 \%$.

\section{DAFTAR PUSTAKA}

[1] Kapdi, SS., Vijay, V.K., Rajesh, S.K., Prasad, Rajendra. 2004. Biogas Scrubbing, Compression and Storage: Perspective and Prospectus in Indian Context. Centre for Rural Development and Technology, Indian Institute of Technology, New Delhi 110 016, India.

[2] Widhiyanuriyawan, Denny, Hamidi, Nurkholis. 2013. Variasi Temperatur Pemanasan Zeolite alam-NaOH Untuk Pemurnian Biogas. Jurnal Energi dan Manufaktur Vol.6, No.1, April 2013: 5363.

[3] Price, E.C and Cheremisinoff, P.N. 1981. Biogas Production and Utilization. Ann Arbor Science Publishers, Inc. United States of America.

[4] Widhiyanuriyawan, Denny. 2014. Biogas Purification Using Natural Zeolite and $\mathrm{NaOH}$. Applied Mechanics and Materials. 664: $415-418$.
[5] Sugiarto., Oerbandono, Tjuk, Widhiyanuriyawan, Denny., Putra, Faruq Syah Permana. 2012. Purifikasi Biogas Sistem Kontinyu Menggunakan Zeolit. Jurnal Rekayasa Mesin Vol.4, No.1 Tahun 2013 1-10.

[6] Prasetya, andhika, Widhiyanuriyawan, Denny., Sugiarto. 2012. Pengaruh Konsentrasi $\mathrm{NaOH}$ Terhadap Kandungan Gas $\mathrm{CO}_{2}$ Dalam Proses Purifikasi Biogas Sistem Continue. Universitas Brawijaya.

[7] Hamidi, Nurkholis, Wardana, ING, Widhiyanuriyawan, Denny. 2011. Peningkatan Kualitas Bahan Bakar Biogas Melalui Proses Pemurnian Dengan Zeolit Alam. Jurnal Rekayasa Mesin Vol 2, No. 3 Tahun 2011: 227-231; Universitas Brawijaya.

[8] Amrulloh Z.A, Hanif. 2014. Sintesis Zeolit Berbasis Silika Sekam Padi Dengan Metode Elektrokimia Sebagai Adsorben Rhodamin B. Universitas Lampung.

[9] Bonenfant, Danielle. Kharuone, Mourad, Niquitte Patrick. 2008. Advances in Principal Factor Influencing Carbon Dioxide Adsorbsion on Zeolites. STEPPE École de Technologie Supérieure, Département de Génie de la Construction, 1100, Notre Dame Ouest, Montréal, QC, H3C 1K3, Canada. 